\title{
Approach Considerations in Aircraft with High-Lift Propeller Systems
}

\author{
Michael D. Patterson* and Nicholas K. Borer ${ }^{\dagger}$ \\ NASA Langley Research Center, Hampton, VA, 23681
}

\begin{abstract}
NASA's research into distributed electric propulsion (DEP) includes the design and development of the X-57 Maxwell aircraft. This aircraft has two distinct types of DEP: wingtip propellers and high-lift propellers. This paper focuses on the unique opportunities and challenges that the high-lift propellers - i.e., the small diameter propellers distributed upstream of the wing leading edge to augment lift at low speeds-bring to the aircraft performance in approach conditions. Recent changes to the regulations related to certifying small aircraft (14 CFR §23) and these new regulations' implications on the certification of aircraft with high-lift propellers are discussed. Recommendations about control systems for high-lift propeller systems are made, and performance estimates for the X-57 aircraft with high-lift propellers operating are presented.
\end{abstract}

\section{Nomenclature}

$\begin{array}{ll}A R & \text { aspect ratio } \\ C_{D} & \text { drag coefficient } \\ C_{L} & \text { lift coefficient } \\ C_{D 0} & \text { parasite drag coefficient } \\ C_{L_{\mathrm{AOA}}} & \text { lift coefficient generated by angle of attack } \\ C_{L_{\mathrm{blowing}}} & \text { lift coefficient generated by the slipstreams of high-lift propellers } \\ \left(\Delta C_{L}\right)_{\text {approach }} & \text { lift coefficient margin in approach } \\ e_{0} & \text { Oswald efficiency factor } \\ K & \text { induced drag factor } \\ L & \text { lift } \\ V & \text { velocity } \\ V_{a} & \text { axial velocity } \\ V_{S 0} & \text { stall speed in the landing configuration } \\ V_{S 1} & \text { stall speed in a specific configuration } \\ S u b s c r i p t s & \\ \text { blown } & \text { with high-lift propellers operating } \\ \text { max } & \text { maximum } \\ \text { min } & \text { minimum } \\ \text { unblown } & \text { without high-lift propellers operating } \\ R E F & \text { at the reference landing approach speed } \\ S y m b o l s & \\ \alpha & \text { angle of attack } \\ \rho & \text { density } \\ & \end{array}$

\footnotetext{
*Aerospace Engineer, Aeronautics Systems Analysis Branch, 1 N. Dryden St. MS 442, AIAA Member.

$\dagger$ Technical Lead, Aeronautics Systems Analysis Branch, 1 N. Dryden St. MS 442, AIAA Senior Member.
} 


\section{Introduction}

NASA has been developing the X-57 aircraft the past few years as a part of the Scalable Convergent Electric Propulsion Technology Operations Research (SCEPTOR) project. ${ }^{8}$ The goal of this project is to demonstrate in flight a 3.5 to 5.0 times reduction in the energy used by the aircraft in cruise while still maintaining effectively equivalent (if not even improved) low-speed performance as the baseline aircraft. The $\mathrm{X}-57$ can achieve these lofty goals through employing distributed electric propulsion (DEP), which involves distributing electric motors and associated propulsors around an aircraft to achieve synergistic integration benefits.

There are many potential forms of distributed electric propulsion; in fact, the imagination is likely the only limit in conceiving of manners of employing DEP on aircraft. The motivation for the present work stems from the ideation of Moore and Fredericks who proposed the e-ATLIT ${ }^{1}$ and LEAPTech ${ }^{2}$ aircraft concepts. Both of these concepts employed three distinct forms of DEP: wingtip propellers, high-lift propellers, and a rearfuselage boundary layer ingestion (BLI) propeller. Wingtip propellers can reduce the total power required compared to conventional propeller installations. ${ }^{3,5,6}$ BLI propellers can also operate with efficiencies of over $100 \%$ by accelerating the region of flow whose velocity has been reduced near the surface of the aircraft. ${ }^{4}$ High-lift propellers increase the lift generated at low speeds by accelerating the flow over the wing and stowing against the nacelle during higher-speed flight to reduce drag, thus acting as a form of high-lift device.

NASA began investigating the potential benefits of high-lift propellers in the LEAPTech project. ${ }^{7}$ The LEAPTech project sought to rapidly assess the potential lift augmentation from high-lift propellers by fabricating a mobile ground truck test rig on which a full-scale wing and high-lift propeller system could be placed. A new wing including 18 high-lift propellers was designed and tested. Initial tests of these high-lift propellers confirmed that large lift augmentation was achievable; therefore, NASA began to explore the potential aircraft system-level efficiency gains that could be obtained by combining high-lift propellers with wingtip propellers in the SCEPTOR project.

The SCEPTOR project is developing the X-57 aircraft, which is a modified Tecnam P2006T - a four seat, light twin-engine trainer. To create the X-57, the original wing of the P2006T will be removed and replaced with a smaller wing employing a DEP system consisting of two wingtip propellers and twelve highlift propellers. A rendering of the future X-57 vehicle can be seen in Fig. 1. Further details on the overall design of the X-57 can be found in Ref. 8 and more specifics on the high-lift propeller system design can be found in Refs. 9 and 10.

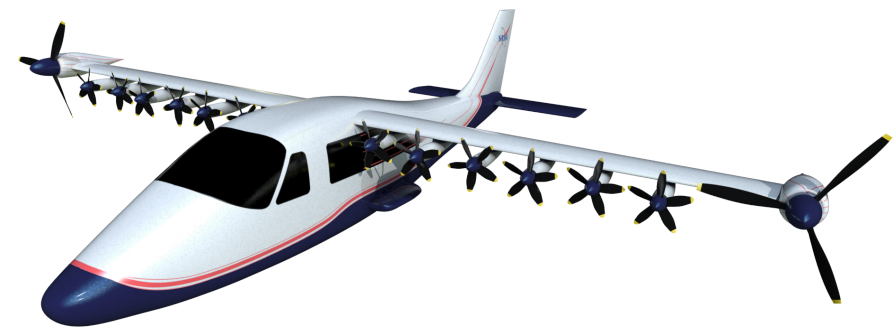

Figure 1. Rendering of the X-57 aircraft

This paper focuses on the unique opportunities and challenges that high-lift propellers present the aircraft designer and operator at low flight speeds. Specifically, the performance of the aircraft in landing approach and how that performance varies with altitude are discussed. The novel performance characteristics of aircraft with high-lift propellers has implications for how the high-lift propellers should be designed and controlled, and these implications are explored in this paper.

\section{Approach and Landing Performance of Aircraft with High-Lift Propellers}

The most critical low-speed performance requirement on many aircraft is the ability of the aircraft to approach and land at a reasonable speed. Generally, small wings are desirable for cruise flight because the drag of a small wing is less than that of a large wing and still capable of producing sufficient lift at higher speeds. However, too small of a wing may lead to high approach and landing speeds, which can increase 
landing distances and decrease the safety of the aircraft since the increased kinetic energy carried with a higher speed must be dissipated in the event of an emergency landing.

Conventional aircraft generally trade some high-speed performance for acceptable low-speed performance through a combination of larger-than-optimal wings for cruise flight along with conventional high-lift devices such as flaps. These aircraft are able to approach and land with little to no thrust required since the potential energy of the vehicle can be traded for kinetic energy as the aircraft descends. In contrast, aircraft with high-lift propellers will likely be designed with smaller wings, which will require blowing from the high-lift props to meet the stall and approach speed requirements. These props will inherently produce thrust in lowspeed conditions, and it is possible that the thrust generated to provide sufficient lift will make it impossible for the aircraft to descend at the desired speed. The modeling described in this section will provide insight into this interesting new problem.

Additionally, the regulations associated with low-speed flight will be discussed in this section. Current regulations will be examined and modifications of these regulations based on the novel performance characteristics of aircraft with high-lift propellers will be proposed. Ultimately, these regulations will dictate how high-lift propeller systems should be designed.

\section{A. Regulations Related to Stall and Approach Speeds}

The FAA has recently rewritten the regulations for small aircraft in 14 CFR $\S 23$, which is more commonly called "Part 23." This rewrite represents a paradigm shift in the regulations from prescriptive design requirements to performance-based, industry-consensus standards. The new regulations were finalized at the end of 2016 and go into effect in August 2017.

Aircraft with DEP such as X-57 have been part of the motivation for this rewrite of the FAA regulations. Under the former Part 23 regulations, an aircraft like X-57 would have been uncertifiable for several reasons including its all-electric propulsion system as well as its small wing which is enabled by the high-lift propeller system. The new language in Part 23 provides a pathway for new technologies like DEP to be certified by moving to consensus standards.

In this section, we compare the new regulations with their former counterparts and provide our own thoughts on how manufacturers may be able to adhere to the new Part 23 language. We use existing versions of consensus standards when applicable, but since modifications to these standards may occur, the reader should verify the references made here to those standards are still valid. This section is essentially modified from the discussion of the former regulations and their implications on aircraft with high-lift propeller systems presented in Ref. 9 .

Two of the most critical regulations for high-lift propeller systems in the former Part 23 are 14 CFR $\S 23.49$, which defined stall speeds, and $§ 23.73$, which defined the reference approach speed. Specifically, the reference approach speed was defined to be $30 \%$ higher than the stall speed, and the stall speed (for reciprocating engine aircraft) was defined as the stall speed with engines at idle (with other caveats). These rules effectively prohibited any credit be taken for the lift augmentation from high-lift propellers since the reference approach speed used in determining landing performance would be set by the unblown stall speedi.e., the stall speed of the aircraft without the high-lift propellers operating.

The new regulations are less prescriptive than the former rules and provide an avenue for high-lift propeller systems to be certified. Specifically, the stall speed can now be determined with power set at "[a] nominal thrust for propulsion systems that are used for thrust, flight control, and/or high-lift systems" [14 CFR $\S 23.2110]$. Additionally, there is no longer a reference approach speed defined directly in terms of the stall speed. The new regulations instead require that "stall speed safety margin" (as well as a few other factors that are less relevant to the high-lift propeller system in particular) be considered when determining landing performance -i.e., setting the reference approach speed [14 CFR §23.2130].

This stall speed safety margin is likely included to account for both pilot error and factors beyond the pilot's control such as wind gusts and low-level wind shear. The pilot must be able to react to any changes in aircraft attitude or airspeed without stalling or otherwise losing control of the airplane. Ultimately, the industry consensus standards will define what margin should be kept, but these are still not finalized. Consequently, former Part 23 regulations may provide some insight into what margin should be acceptable.

The former Part 23 specified a $30 \%$ stall speed margin (in 14 CFR $\S 23.73$ ). For typical aircraft, beginning with a similar velocity margin may be a logical starting point. However, in novel aircraft designs including those with high-lift propellers like X-57, additional consideration is required. In short, a simple velocity margin is likely insufficient for aircraft with high-lift propellers because these aircraft produce lift differently 
than conventional aircraft, and even at a 30\% velocity margin it is possible for the aircraft to be in an unsafe flight condition. A more thorough explanation is provided throughout the remainder of this section and the following section.

Aircraft with high-lift propellers generate lift differently than conventional aircraft. Whereas a conventional aircraft in a specified configuration at a certain airspeed and altitude can only increase lift through increasing the angle of attack, ${ }^{a}$ aircraft with high-lift propellers can create additional lift at the same angle of attack through increasing the blowing from the props. The induced velocity and the component of thrust in the lift direction from the propellers adds a new degree of freedom to produce lift.

Because these two mechanisms for producing lift in an aircraft with high-lift propellers can be modified independently, ${ }^{\mathrm{b}}$ it is helpful to decompose the total lift generated into two components: the angle of attack contribution and the blowing contribution. Mathematically, this relationship can be expressed as Eq. 1, where $C_{L_{\mathrm{AOA}}}$ is the $C_{L}$ contribution from the angle of attack (i.e., the lift coefficient without any blowing) and $C_{L_{\text {blowing }}}$ is the additional lift generated by the high-lift propellers' slipstreams (i.e., the total lift less the unblown lift).

$$
C_{L}=C_{L_{\mathrm{AOA}}}+C_{L_{\mathrm{blowing}}}
$$

To understand the significance of these two separate lift producing mechanisms on the concept of a "stall speed safety margin" in approach, one must realize that a velocity margin above stall speed can also be viewed as a lift coefficient margin-i.e., the difference between the maximum $C_{L}$ and the operating $C_{L}$. We will denote the lift coefficient margin as $\left(\Delta C_{L}\right)_{\text {approach }}$, the approach speed as $V_{R E F}$, and the stall speed as $V_{S 1}$ (using some terminology from the old Part 23). Since $C_{L}=2 L /\left(\rho V^{2} S\right)$ and the lift produced at the approach speed and stall speed must be the same, the lift coefficient at the approach speed can be written as $C_{L_{\mathrm{REF}}}=C_{L_{\max }}\left(V_{S 1} / V_{R E F}\right)^{2}$. Consequently, the lift coefficient margin is

$$
\left(\Delta C_{L}\right)_{\text {approach }}=\left(1-\left(V_{S 1} / V_{R E F}\right)^{2}\right) C_{L_{\max }} .
$$

Ultimately, Eq. 2 shows that a stall speed safety margin (i.e., the ratio of $V_{S 1}$ and $V_{R E F}$ ) can be equated to a $C_{L}$ margin. We will use these terms (i.e., stall speed safety margin and $C_{L}$ margin) more-or-less synonymously moving forward.

Because conventional aircraft create $C_{L}$ entirely by controlling the angle of attack for given flight conditions and vehicle configuration, the $C_{L}$ margin for these aircraft can also be considered an angle of attack margin, which we denote as $(\Delta \alpha)_{\text {approach }}$. In contrast, aircraft with high-lift propellers can create $C_{L}$ with angle of attack as well as with blowing from the high-lift props. Consequently, their total lift coefficient margin is comprised of an angle of attack portion as well as a portion available from increasing propeller blowing. Different manners of dividing the angle of attack and blowing portions of the total stall speed margin will be explored in the next section.

Before considering possible ways of dividing margin in aircraft with high-lift propellers, understanding the margins found in existing aircraft under the former Part 23 can provide a guideline for the sort of margins that should be certifiable under new regulations. The former Part 23 (in 14 CFR §23.73) mandated a 30\% stall speed margin so that $V_{R E F}=1.3 V_{S 1}$. Substituting this relationship into Eq. 2 leads to Eq. 3, which results in a $C_{L}$ margin of approximately $41 \%$ of the aircraft's maximum $C_{L}$.

$$
\left(\Delta C_{L}\right)_{\text {approach }}=\left(1-1 / 1.3^{2}\right) C_{L_{\max }} \approx 0.41 C_{L_{\max }}
$$

Since many general aviation aircraft have high-lift systems that produce $C_{L_{\max }}$ values of approximately 1.5 to 2 , these aircraft have $C_{L}$ margins of approximately 0.61 to 0.82 at the reference approach speed.

To estimate the angle of attack margins associated with these $C_{L}$ margins, we can use approximations of the lift curve slopes of the full aircraft. We will consider roughly bounding cases of the lift curve slope of $2 \pi$ and 4.0 per radian, where $2 \pi$ is taken from thin airfoil theory as a rough upper limit and 4.0 is taken as a rough lower limit. The angle of attack margins corresponding to these lift curve slopes and $C_{L}$ margins of

a There are many small aircraft with propellers installed upstream of the wing leading edge (e.g., a typical light twinengine aircraft). The slipstreams from these propellers can have significant impacts on the lift generated. However, since these propellers are not specifically designed to augment lift and very low powers are typically used in approach, these aircraft control lift during approach (at a given speed) almost entirely via angle of attack.

b There is certainly a coupling between the propeller power setting and the local angle of attack of wing sections downstream of the propellers. However, there is still some degree of independent control of the lift from propeller blowing and angle of attack: the pilot could increase/decrease blowing at the same aircraft attitude or the pilot could change aircraft attitude with the propellers at the same setting to vary lift. 
approximately 0.61 to 0.82 are approximately $5^{\circ}$ to $12^{\circ}$. Since aircraft with high-lift propellers can create lift with angle of attack and blowing, the angle of attack margin required for safe operation can be reduced from these values. However, it is likely necessary for safety to carry some non-zero angle of attack margin at the reference approach speed (and ideally at all velocities down to stall speed) to provide margin for pilots to react to off-nominal conditions such as failures or wind gusts entirely with angle of attack control.

We propose that high-lift propeller systems that provide $C_{L}$ margins of approximately 0.61 to 0.82 should satisfy the new Part 23's mandate of maintaining a "stall speed safety margin" so long as there is also some non-zero angle of attack margin. ${ }^{c}$ Stated differently, the reference approach speed must be greater than the unblown stall speed of the wing to account for off-nominal situations such as a full system power loss. ${ }^{\mathrm{d}}$ The safety implications of certifying aircraft with high-lift propellers in a different manner than conventional aircraft is explored in the following section.

\section{B. Exploration of Lift Coefficient Margin and Potential Approach Profiles of Aircraft with High-Lift Propellers}

The total $C_{L}$ margin desired and the division of this margin between the angle of attack and blowing components in high-lift propeller aircraft will have implications on the maximum power required from the high-lift propeller system and the flight condition at which the critical power requirement to the system will be set. In this section, we will explore a few examples of how high-lift propeller systems can be operated to provide the desired lift with each showing a different ultimate lift coefficient margin and manner in which that $C_{L}$ margin is comprised. Here, since we are analyzing the X-57 aircraft and not designing a new aircraft, our discussion will focus on the performance. A discussion of the impacts of various approach profiles on the design point for high-lift propeller systems can be found in Ref. 9.

\section{Approach Profiles}

Part 23 regulations only imply a $C_{L}$ margin at a single speed: the reference approach speed. In an operational setting, the aircraft will initially approach at this speed, but will decrease its speed before landing. To reduce the landing distance, the speed should be decreased to near stall before touchdown. The act of decreasing speed through the approach is accompanied by an increase in the lift coefficient, and, consequently, a reduction in the $C_{L}$ margin. The variation of the lift coefficient through the act of decreasing the velocity is termed here the "approach profile," and the $C_{L}$ margin that is associated with an approach profile is called the "lift coefficient margin profile." These profiles can be visualized as plots of either the $C_{L}$ or $\left(\Delta C_{L}\right)_{\text {approach }}$ as a function of flight speed such as those shown in Fig. 2. The approach profile can be seen in Fig. 2(a), and the associated margin is plotted in Fig. 2(b). The lift coefficient margin shown begins at the level required by the former Part 23 regulations where $V_{R E F}=1.3 V_{\text {stall }}$.

There are many possible approach profiles that can be flown in aircraft with high-lift propellers because the blowing can be varied to augment different amounts of lift. The following example profiles will be presented here:

1. Minimum blowing approach,

2. Linear variation of $C_{L}$ generated by angle of attack with velocity (a.k.a., "Linear $C_{L_{\mathrm{AOA}}}$ ") approach, and

3. Maximum blowing approach.

These examples are non-exhaustive and are provided to show "bounds" on how the high-lift propellers could operate throughout an approach.

The first two of these example approach profiles are illustrated in Fig. 3. ${ }^{\text {e }}$ The plots in this figure show velocities ranging from the blown stall speed, $\left(V_{\text {stall }}\right)_{\text {blown }}$, up to the unblown approach speed, which is the reference approach speed that the former Part 23 would have required for an aircraft with high-lift propellers since no credit was allowed for blowing (i.e., $\left.\left(V_{\text {approach }}\right)_{\text {unblown }}=1.3\left(V_{\text {stall }}\right)_{\text {unblown }}\right)$. In each profile, the total required $C_{L}$ is generated through a combination of angle of attack and blowing (as discussed above in reference to Eq. 1), and these combinations are described below.

\footnotetext{
${ }^{\mathrm{c}}$ The precise minimum amount of $(\Delta \alpha)_{\text {approach }}$ is debatable.

${ }^{\mathrm{d}}$ In a wisely-designed power system, the probability of a complete power loss is incredibly small. X-57 will use multiple buses so that any one failure would cause at most half of the high-lift propellers to shut down. See Ref. 11 for more information.

e The maximum blowing profile cannot be illustrated generically because it depends on the amount of blowing available. See discussion in Section II.B.4.
} 


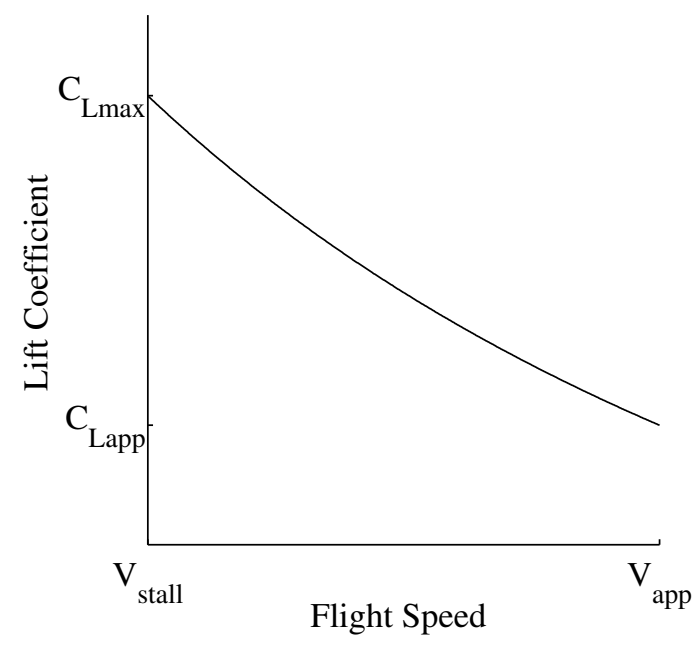

(a) Approach profile

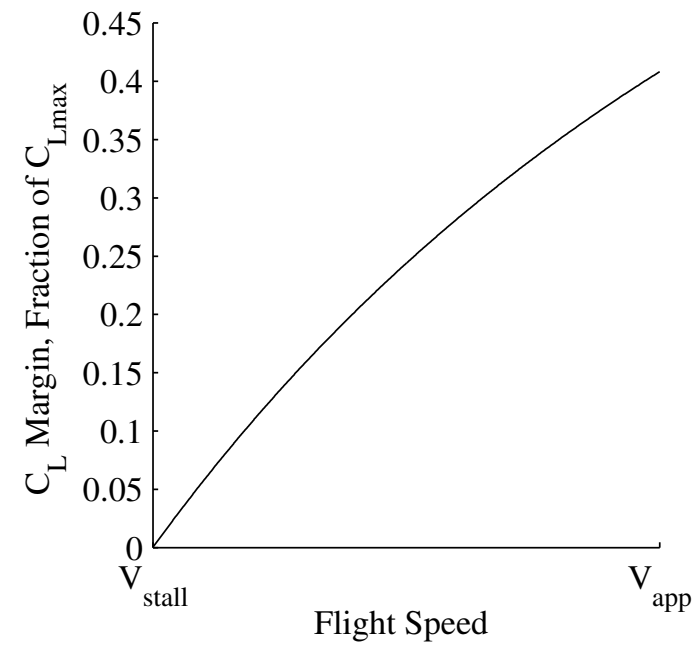

(b) Lift coefficient margin profile

Figure 2. Generic representation of an approach profile and the associated lift coefficient margin profile

The minimum blowing approach ${ }^{\mathrm{f}}$ creates as much lift from angle of attack as possible, and is depicted graphically in Fig. 3(a). From the unblown approach speed to the unblown stall speed, no blowing is utilized so $C_{L}=C_{L_{\mathrm{AOA}}}$. Once reaching $\left(V_{\text {stall }}\right)_{\text {unblown, }}$, no additional lift can be produced from angle of attack, so blowing must be utilized to maintain sufficient lift at lower speeds. This approach forms an absolute lower bound on the blowing power that may be required because it utilizes as little blowing as possible. It should be stressed that this approach is not recommended to be flown because there is no angle of attack margin over a range of speeds. It is included here strictly to provide a lower bound on the required blowing.

The linear $C_{L_{\mathrm{AOA}}}$ approach is illustrated in Fig. 3(b). In this approach profile, the $C_{L}$ from angle of attack is increased linearly as the velocity is decreased. The blowing is also increased with decreasing velocity to maintain the required overall lift. This approach profile represents a "happy medium" in lift generation between angle of attack and high-lift propeller blowing.

The final example approach profile is the maximum blowing approach. In this approach, the propellers are operated at their maximum continuous torque limit throughout the approach. The precise lift augmentation from this operation depends on the detailed wing and propeller geometries as well as the torque and power limits of the motors. Consequently, no generic plot of this profile can be made. In contrast to the other profiles where the desired blowing is first specified, in this profile the blowing "falls out" from the existing geometry and motor capabilities. So long as the blowing is sufficient to produce the required lift throughout the approach profile, this approach is the most conservative approach in that it will require the least amount of lift from angle of attack of any of the approach profiles; however, it will be the most taxing approach on the aircraft's energy supply and high-lift propeller system.

In each of the example profiles, the $C_{L}$ margin and the contributions of angle of attack and blowing to this margin vary. In the discussion below, the X-57 aircraft is analyzed in each of these approach profiles to demonstrate these changes.

\section{Approach Thrust Issues and High-Lift Drag Model}

The approach profile flown will have implications on the blowing required from the high-lift propellers and, therefore, the thrust produced by these props. If the total thrust is greater than the drag of the aircraft, then the aircraft will accelerate. Consequently, high-lift propeller thrust may make descent and landing when flying the desired profile impossible. The drag of the aircraft in high-lift conditions with propeller blowing must be estimated because this drag will determine an effective ceiling on the total thrust allowable from the high-lift propellers.

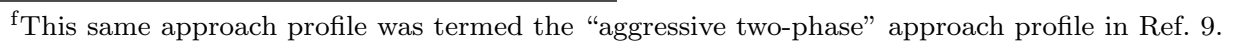




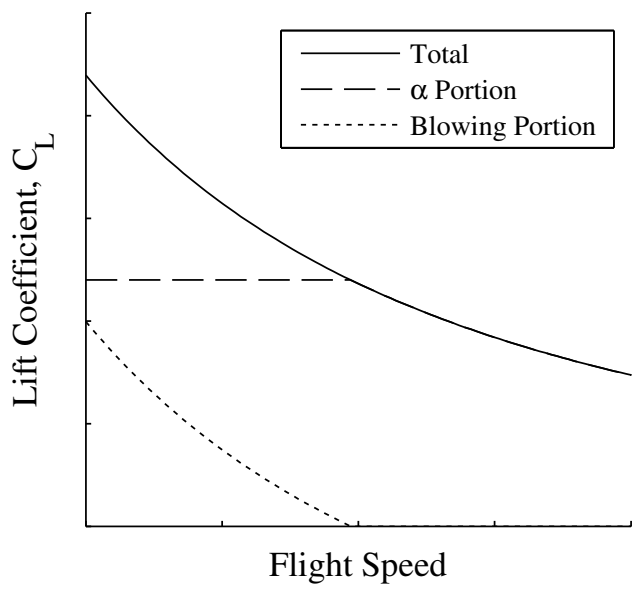

(a) Minimum blowing approach profile

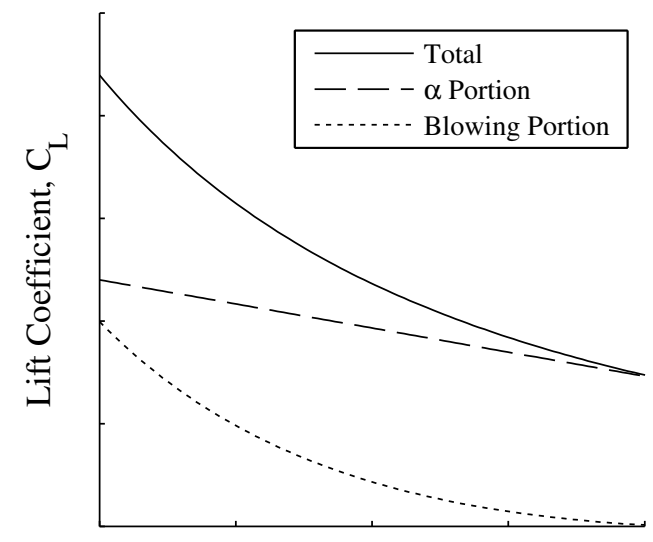

Flight Speed

(b) Linear $C_{L_{\mathrm{AOA}}}$ approach profile

Figure 3. Generic representations of example approach profiles for aircraft with high-lift propellers

Unfortunately, the drag generated from propeller blowing is very difficult to predict-particularly in the early design phase. The propeller slipstreams flow only over portions of the wing varying the local velocity, impacting the transition location, modifying flow separation locations, and causing very "jagged" lift distributions; each of these conditions greatly complicates drag prediction. Additionally, high-lift propellers will often be accompanied by other high-lift devices such as flaps, which makes the drag prediction even more difficult.

For the purposes of demonstrating the general trends that may occur and the types of information pertinent to an aircraft designer, a simple high-lift drag model is adopted here. This model is based on a two-parameter drag polar of the form $C_{D}=C_{D 0}+K C_{L}^{2}$, where $C_{D 0}$ is assumed to be constant and $K$ varies with propeller blowing. This model is very approximate and is used only as an initial screening to estimate the likelihood of the vehicle producing excess thrust. As all the details of the X-57 design are finalized, higher-fidelity modeling (e.g., CFD) and/or wind tunnel tests will be performed to more accurately estimate the drag prior to any flight testing.

The parasite drag coefficient, $C_{D 0}$, is estimated with handbook component drag buildup methods incorporating form factors and wetted areas along with an estimate for the additional parasite drag from the flap proposed by Raymer. ${ }^{12}$ For X-57 with fully deployed flaps, ${ }^{g}$ the $C_{D 0}$ is estimated to be $0.0760,{ }^{\mathrm{h}}$ where approximately 289 counts are related to the flap and the rest of the aircraft comprises the other 471 counts.

The $K$ parameter for the induced drag is calculated from Eq. 4, where $A R$ is the aspect ratio and the Oswald efficiency factor, $e_{0}$, decreases with high-lift propeller blowing.

$$
K=1 /\left(\pi e_{0} A R\right)
$$

The variation of $e_{0}$ in this model is derived from observations of the induced drag and span efficiency predicted by various members of the SCEPTOR project team for the LEAPTech wing and X-57 aircraft. Although many of these results are unpublished, Stoll presents some of these calculations for the LEAPTech configuration. ${ }^{13}$ Ultimately, these simulations indicate that the effective span efficiency could reach values on the order of 0.5 or lower in situations with high-lift propeller blowing. These low span efficiencies are the result of the propeller slipstream creating very "jagged" wing lift distributions and other local flow phenomena. ${ }^{\mathrm{i}}$

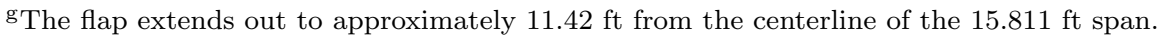

h Although this $C_{D 0}$ value may seem high, recall that the wing area of the X-57 is reduced by approximately $40 \%$ compared to typical general aviation aircraft. Since $C_{D 0}$ is normalized by a smaller reference area, the drag coefficient for X-57 is greater than most GA aircraft.

iThe Oswald efficiency factor, $e_{0}$, differs from the span efficiency factor, $e$. The span efficiency factor only captures the changes in drag from non-elliptic lift distributions. The Oswald efficiency factor considers both the deviation of the lift distribution from the elliptic shape as well as the increases in wing profile drag with lift. 
To estimate how the Oswald efficiency may vary with blowing, simulations were performed for an earlier candidate geometry of the X-57 aircraft with VSPAero, which is a vortex lattice aerodynamic solver developed by Kinney at NASA Ames. ${ }^{13,14}$ For these simulations, the propellers were modeled as elliptically loaded actuator disks based on an inviscid formulation by Conway ${ }^{15}$ with viscous corrections included for the swirl. ${ }^{16}$ The rotational speed and thrust of the actuator disks were varied at a fixed flight speed and angle of attack, and the span efficiency was calculated. The results from these simulations are shown in Fig. 4. The dashed, dotted, and dashed-dotted curves indicate the results from the VSPAero simulations at freestream speeds of 60 and 75 knots and angles of attack ranging from $3^{\circ}$ to $10^{\circ}$.

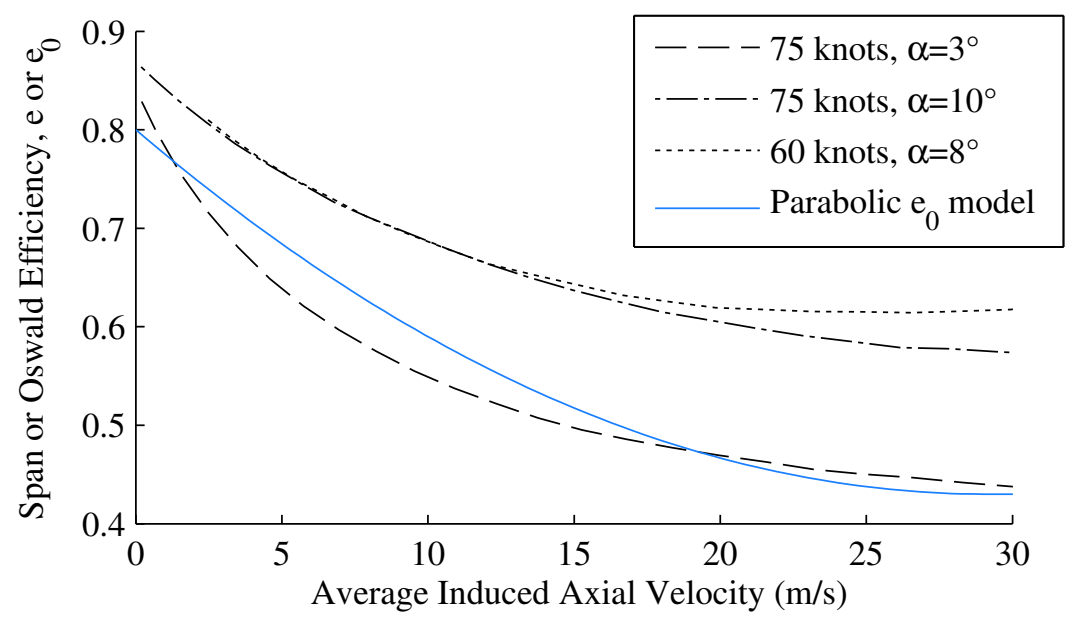

Figure 4. Span efficiency variation at two speeds and multiple angles of attack as predicted by VSPAero for the X-57 configuration with parabolic model overlaid

Although the magnitudes of the span efficiency values from the VSPAero simulations change with operating condition, similar general trends are observed. Specifically, there is a relatively steep decrease in the span efficiency as the blowing is first increased from zero, then the decreases in $e$ become more gradual as the blowing velocity is increased. This variation of span efficiency can be explained through considering the modification of the lift distribution. Even with small axial velocity increases, the swirl from the propellers creates relatively large deviations from the baseline lift distribution. As the blowing is further increased, the swirl increases, which causes even greater departures from an ideal lift distribution; however, the general shape of the lift distribution changes less drastically as this additional blowing is applied. Consequently, the span efficiency begins to exhibit relatively little variation once large values of the induced axial velocity are reached.

Based on these observations, the drag model estimates the variation of $e_{0}$ as a parabolic function of the average induced axial velocity from the high-lift propellers as shown in Eq. 5 where $\left(V_{a}\right)_{\max }=95.8 \mathrm{ft} / \mathrm{s},{ }^{\mathrm{j}}$ $e_{0, \max }=0.8, e_{0, \min }=0.43$, and $V_{a}$ is the average axial velocity from the propeller far-downstream.

$$
e_{0}=\frac{\left(V_{a}-\left(V_{a}\right)_{\max }\right)^{2}}{\left(V_{a}\right)_{\max }^{2}}\left(e_{0, \max }-e_{0, \min }\right)+e_{0, \min }
$$

The implied values for the Oswald efficiency from this model are shown in Fig. 4 by the solid line beginning at $e_{0}=0.8$ at no blowing. A drag model closer to the lower values of the span efficiency from the VSPAero simulations is selected to account for the increases in profile drag and friction drag, which is not directly modeled here but will increase with blowing.

\section{Creating Additional Drag}

For aircraft with high-lift propellers, additional drag sources may be required to mitigate the effects of thrust from the high-lift props. These additional drag sources are only potentially desirable in the approach and

\footnotetext{
jThis $\left(V_{a}\right)_{\max }$ value is higher than any value generated by the $\mathrm{X}-57$ high-lift propellers in the modeling performed in this paper.
} 
landing phase of flight where both high lift and low thrust production is required. Discussion related to several potential drag-producing sources can be found in Ref. 9.

Only a single source of a drag producing device is being considered for the X-57. The power system of the aircraft is being designed so that the wingtip electric motors can be operated in a regenerative mode so that the cruise propellers can windmill and increase the aircraft drag. When attempting to create drag with a propeller, various levels of drag can be produced depending on the rotational speed of the propeller and the pitch of the blades. For the results presented below, we assume the wingtip propellers are operated at their maximum speed of $2700 \mathrm{RPM}^{\mathrm{k}}$ for windmilling and that the isolated prop performance will provide sufficiently accurate predictions of the propellers' performance as-installed upstream of the wingtips. The pitch of the propellers is set such that our simulations of the propeller performance with XROTOR ${ }^{17}$ indicate that the maximum possible power extraction is made with there being no stalled blade sections. ${ }^{1}$

Results below will be presented both with and without the estimated drag contribution from the windmilling propellers for the X-57 aircraft. Such an approach is instructive because it will help indicate if windmilling is required and how much additional drag the cruise propellers can provide.

\section{Approach Performance Estimates}

In this section we present performance estimates for the X-57 aircraft for the three approach profiles discussed above. The following analyses provide insight into the variation of the lift coefficient margin and the "stall speed safety margin" provided by the three approach profiles. Additionally, the results indicate if there may be any resulting acceleration or deceleration of the aircraft when attempting to fly the proposed approach profiles. Any condition where the excess thrust is not zero indicates that the cruise propellers should provide either positive or negative thrust (for negative or positive excess thrust from the high-lift props, respectively) to enable a steady-state approach at a given speed. Ultimately, if the total excess thrust including drag from windmilling the cruise propellers is greater than zero, then such an approach is impossible for the X-57 under the assumptions that the windmilling props are operated as described above and that the models employed here are accurate.

The propeller operating conditions required for the example approach profiles discussed above in Section 1 are analyzed assuming a 5-bladed propeller with the blade geometry shown in Fig. 5 is installed. Although

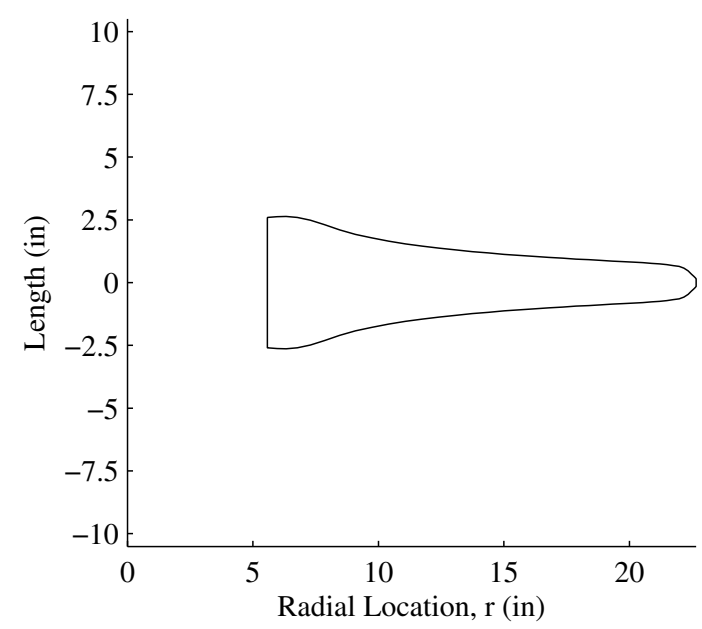

(a) Chord distribution

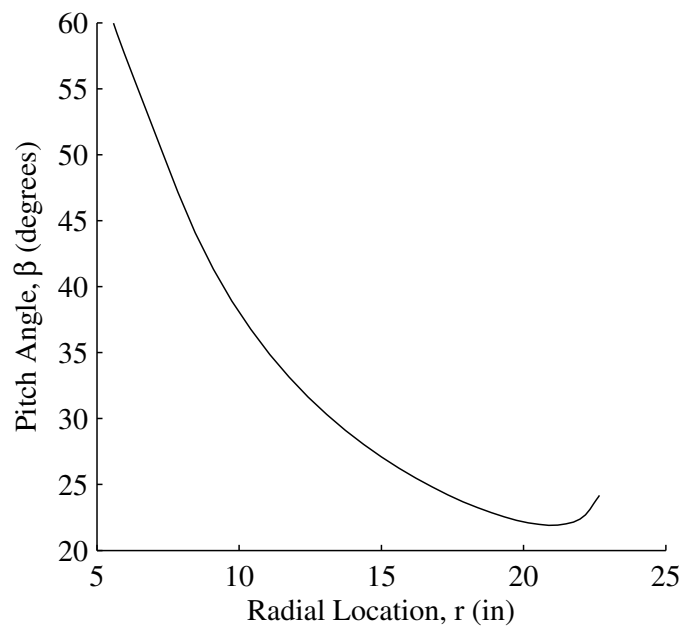

(b) Twist distribution

Figure 5. Non-folding blade design of the 5-bladed high-lift propeller analyzed for approach calculations

\footnotetext{
$\mathrm{k}$ The maximum speed was selected because standard practice when flying aircraft with constant speed propellers is to set the prop speed full forward during approach in case of a go around.

${ }^{1}$ Greater power extraction and drag could be created with different blade pitch settings. (More details on these trends can be found in Ref. 9.) However, the accuracy of the XROTOR model is suspect in these conditions because of the relatively lowfidelity post-stall model. Additionally, avoiding stalled sections should reduce noise from the prop. Ultimately, this approach provides a conservative estimate of the possible drag that can be produced.
} 
this blade is technically a non-folding blade, the performance of the folding blade is shown in Ref. 18 to be nearly the same as the non-folding design.

For the following results, the lift augmentation from the propellers is modeled using the method described in Ref. 9. The aircraft is analyzed as a point mass at an instant in time, and the forces are balanced only in the direction perpendicular to the freestream velocity. The aircraft weighs $3,000 \mathrm{lb}$ and is flying a $3^{\circ}$ glide slope. The high-lift propellers are installed at $\mathrm{a}-1^{\circ}$ incidence angle relative to the wing mean chord line, and the wing mean chord line is inclined at an angle of $1^{\circ}$ to the reference point for measuring angle of attack. This installation implies that at positive angles of attack there will be "flow turning" from the propellers - i.e., the wing will see a reduced angle of attack relative to the freestream. Although this will reduce the effective lift from the wing the prop thrust will directly contribute to lift.

Several other assumptions were made for the following analyses. First, the propellers are analyzed in isolation at a zero-degree angle of attack with XROTOR. In reality they will likely experience a decrease in performance from the calculated values from operating near the wing and at an angle of attack. Second, the aircraft operates along a linear lift curve where zero lift is obtained in the flapped configuration at $-20^{\circ}$ (without propeller blowing) and an unblown $C_{L_{\max }}$ of 2.5 occurs at $10^{\circ}$. Third, the presence of the cruise propellers and whether or not they are feathered, windmilling, or thrusting has no effect on the wing lift or drag.

The results for the three example approach profiles are shown in Fig. 6, Fig. 7, and Fig. 8. Each of these figures contains five sub-figures that show the

(a) lift coefficient profile;

(b) lift coefficient margin profile;

(c) high-lift propeller excess thrust (i.e., the thrust from the high-lift propellers minus the drag of the aircraft), total excess thrust (i.e., the high-lift propeller excess thrust along with additional drag from windmilling the cruise propellers), and thrust of a single high-lift propeller;

(d) high-lift propeller RPM and tip speed; and

(e) torque for each high-lift prop, total power for all the high-lift propellers, and total power including regenerative windmilling of the cruise propellers.

The performance of the aircraft is plotted in all sub-figures from the desired stall speed of 58 knots up to approximately 94 knots, which is 1.3 times the unblown stall speed. The blowing margin shown in the figures assumes that the maximum motor torque is $21 \mathrm{~N}-\mathrm{m}$, which was taken from specifications of the Joby JM1 motor. ${ }^{19}$ Although the precise high-lift motors for X-57 have not been selected, the JM1 was installed on the LEAPTech wing, ${ }^{7}$ the high-lift nacelles were designed to accommodate a motor the size of the JM1, and the final high-lift motor specifications will likely be near this level of torque.

The minimum blowing approach results are shown in Fig. 6. This example profile is the least conservative of all those analyzed and represents an absolute lower-bound on the high-lift propeller requirements. Although theoretically possible to fly, this approach is unsafe and should not be flown in practice because there is no margin to account for sudden angle of attack changes over much of the approach (i.e., from velocities of 58 knots up to approximately 73 knots). However, this profile is useful to indicate if excess thrust from the high-lift propellers will prohibit the aircraft from flying an approach; if this approach cannot be flown without excess thrust, then no approach profile will be feasible.

In this approach for the X-57, the high-lift propellers are inoperative until the aircraft slows to just under 73 knots. As speeds decrease below 73 knots there is a gradual increase in the required RPM, torque, and power. Fig. 6(c) indicates that this approach profile could likely be flown with the current high-lift propeller system since there is negative excess thrust predicted throughout the profile (i.e., positive thrust would be required from the tip propellers to maintain steady flight at any of the speeds analyzed).

As shown in Fig. 6(b), the aircraft could still maintain the same lift coefficient margins as many existing aircraft (i.e., on the order of approximately 0.6 to 0.85 ) if its approach speed was between approximately 73 and 82 knots. However, flight below 73 knots would be unsafe since there is no margin from angle of attack. Additionally, flight near, but above, 73 knots provides very little angle of attack margin. To achieve rough parity with existing GA aircraft in terms of pure angle of attack margin, speeds of approximately 84 to 89 knots would be required. Finally, at the 58 knot speed, a small amount of $C_{L}$ margin from blowing is still present. This indicates that the high-lift propeller system is somewhat oversized to provide the desired blown stall speed of 58 knots. This extra $C_{L}$ margin implies that the actual stall speed of the aircraft could be slightly reduced. This margin was, in fact, designed into the aircraft to account for potential aircraft weight increases and uncertainties in the design and analysis of the high-lift system. 


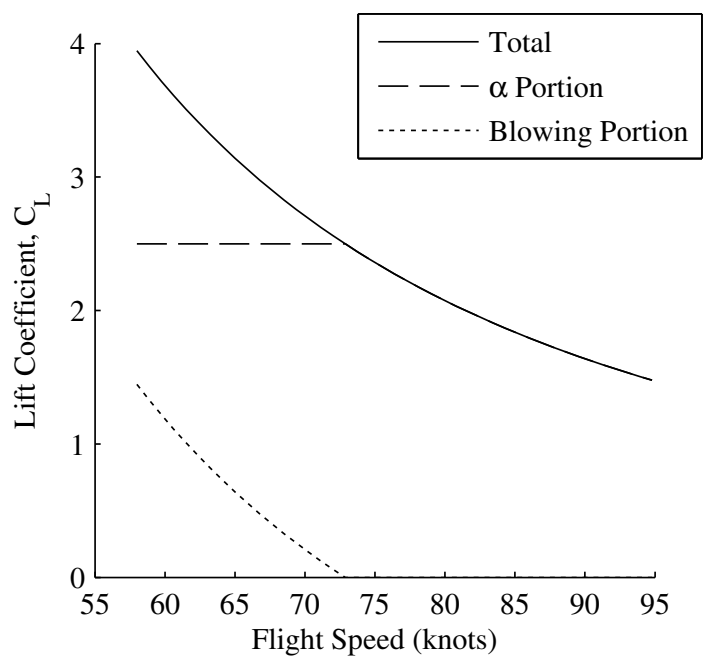

(a) Approach profile

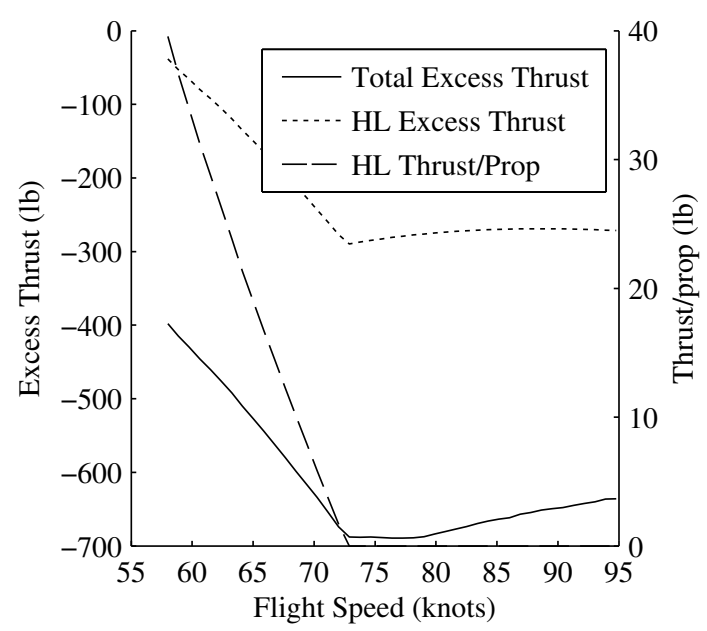

(c) Total excess thrust and high-lift propeller thrust

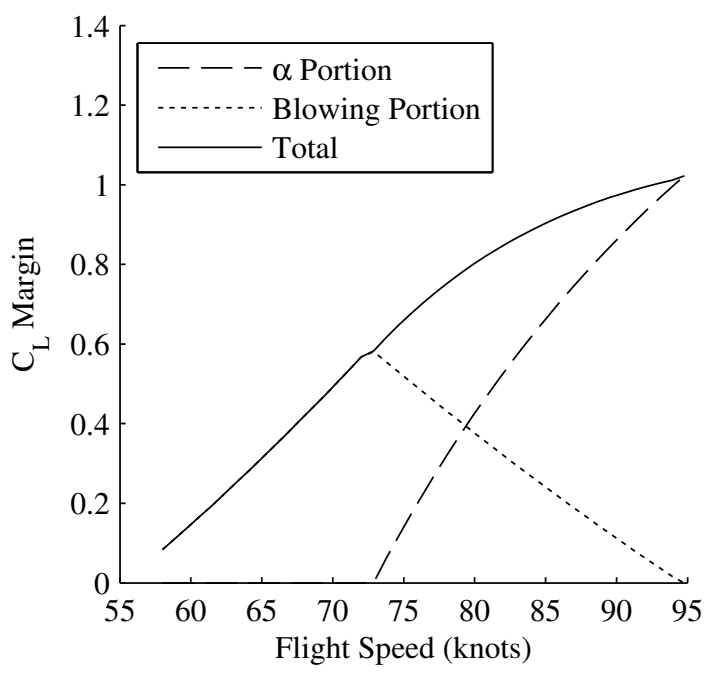

(b) Lift coefficient margin profile

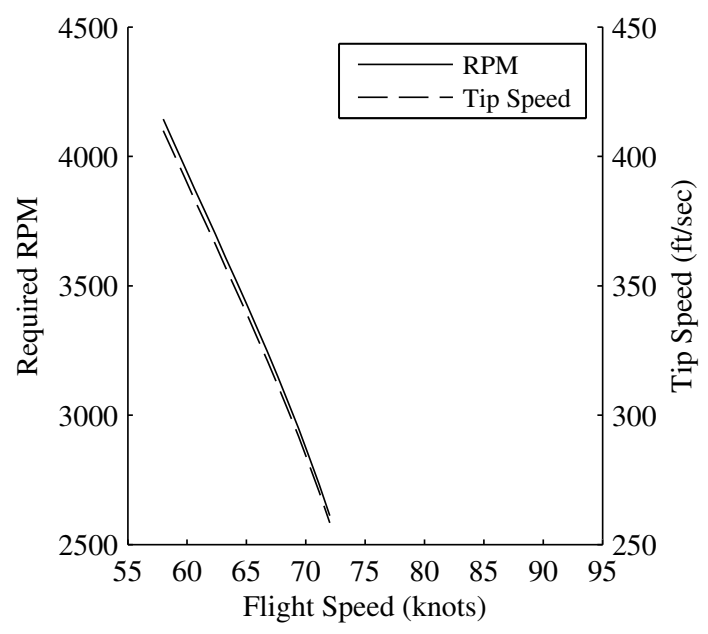

(d) High-lift propeller RPM and tip speed

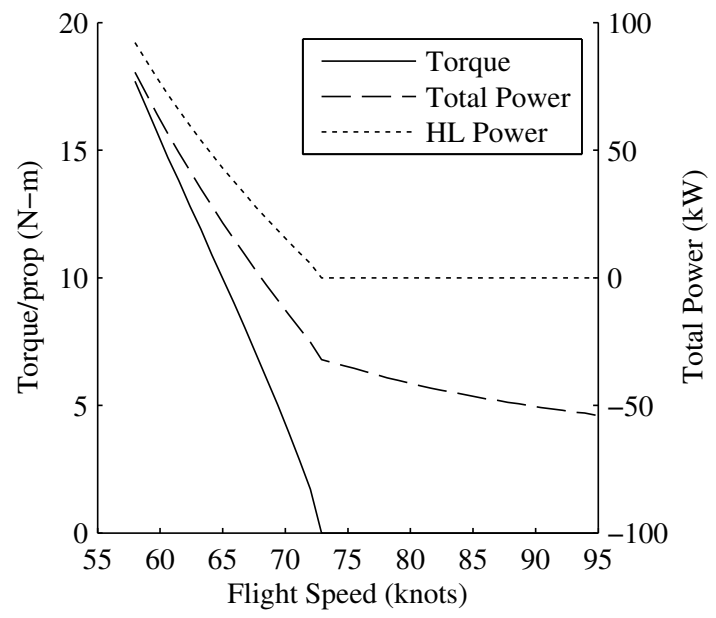

(e) High-lift propeller torque and total power

Figure 6. Minimum blowing approach profile simulation results 


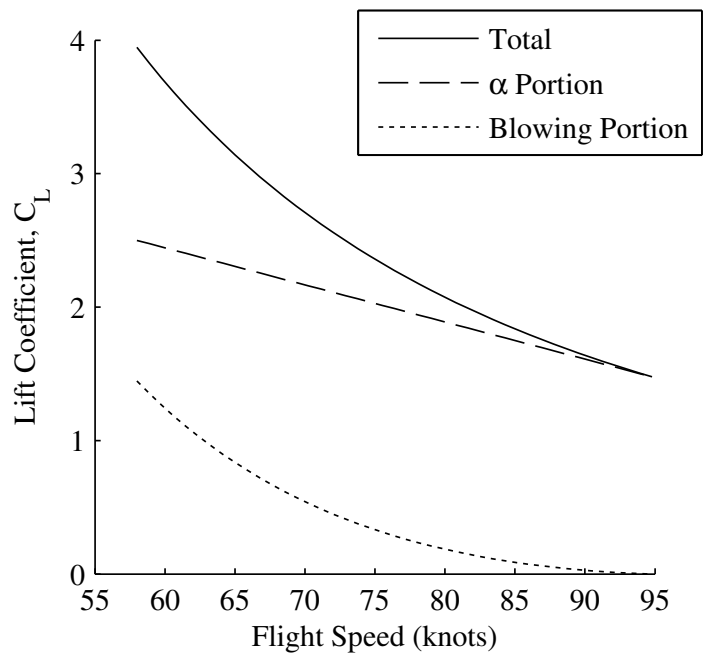

(a) Approach profile

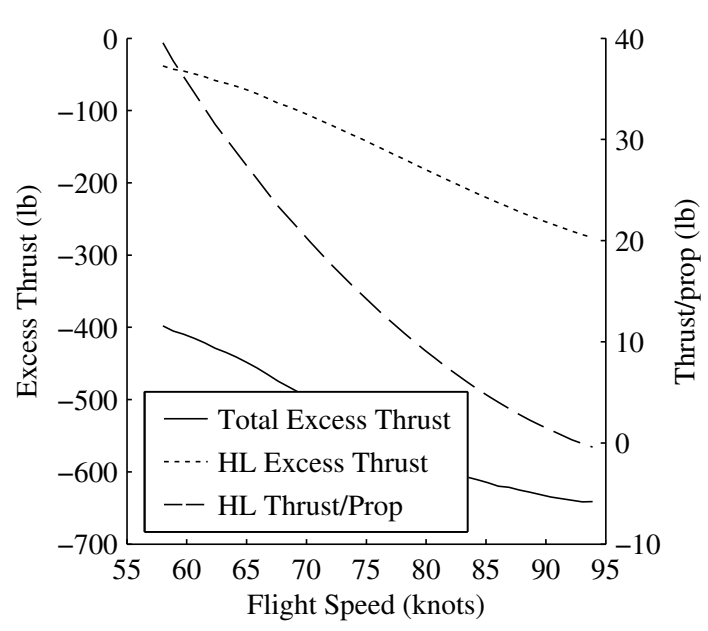

(c) Total excess thrust and high-lift propeller thrust

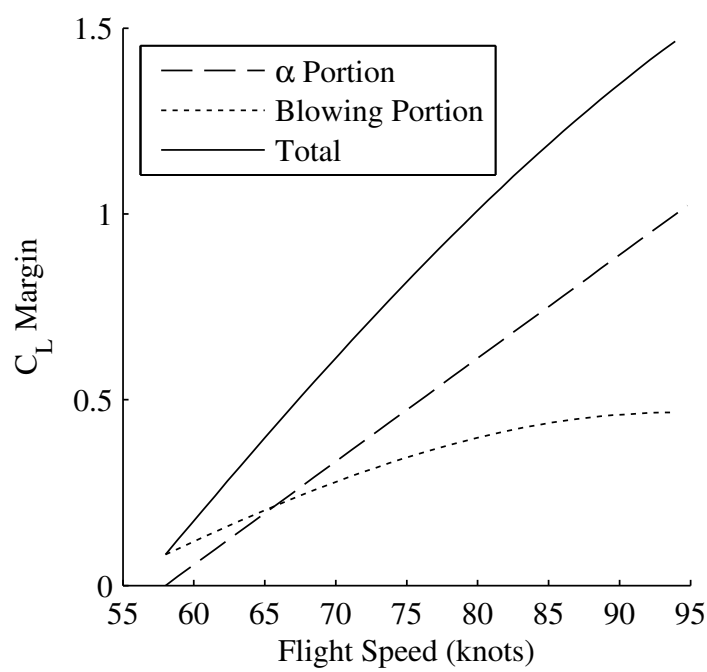

(b) Lift coefficient margin profile

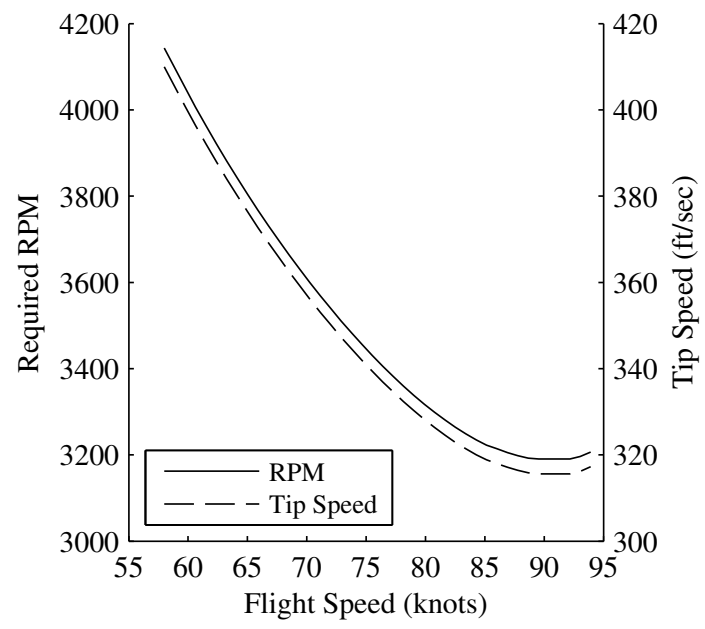

(d) High-lift propeller RPM and tip speed

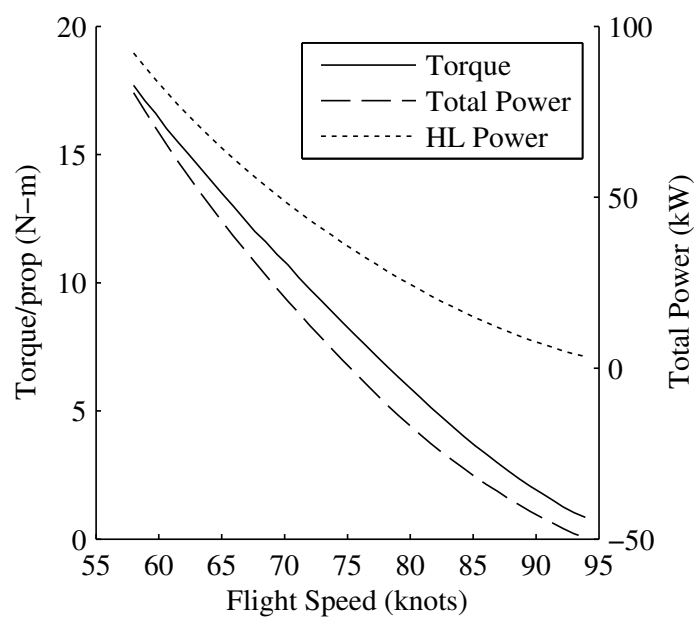

(e) High-lift propeller torque and total power

Figure 7. Linear $C_{L_{\mathrm{AOA}}}$ approach profile simulation results 
The linear $C_{L_{\mathrm{AOA}}}$ approach profile results are shown in Fig. 7. In this approach, the blowing is gradually increased throughout the entire profile with the maximum torque/power condition (i.e., the sizing point) occurring at the stall speed. A near-linear variation of torque with airspeed is required to maintain adequate lift, and the power and RPM exhibit near parabolic variation with speed. The increase in propeller RPM observed in Fig. 7(d) at speeds above approximately 90 knots results from the fact that the high-lift propellers are fixed pitch. Ultimately the high-lift props will begin to pitch out at speeds much greater than 95 knots, making them ineffective at higher velocities.

The lift coefficient margin is shown in Fig. $7(\mathrm{~b})$. The total $C_{L}$ margin is comprised of a combination of blowing and angle of attack over all speeds, with the angle of attack portion being greater than the blowing portion throughout as shown in Fig. 7(b). Unlike the minimum blowing profile that has much greater margin from one source over the other (depending on the velocity), the linear $C_{L_{\mathrm{AOA}}}$ approach provides a balanced margin between angle of attack and blowing, which provides flexibility in adjusting to disturbances. In the minimum blowing approach, the pilot would need to know where margin existed at every speed to correct for a disturbance. At some speeds (i.e., less than approximately 73 knots), it is only appropriate to increase power to the props while at other speeds only angle of attack variations are possible to correct for disturbances. However, with the linear $C_{L_{\mathrm{AOA}}}$ profile, the pilot could always adjust either angle of attack or high-lift power to account for disturbances. Total $C_{L}$ margins similar to typical GA aircraft occur at speeds between approximately 70 and 75 knots. As with the minimum blowing profile, there is a non-zero $C_{L}$ margin at the desired stall speed from propeller blowing, indicating that the actual blown stall speed is less than 58 knots.

There is relatively little concern about excess thrust from this Linear $C_{L_{\mathrm{AOA}}}$ profile as shown in Fig. 7 (c). Only at speeds close to the desired blown stall speed of 58 knots does the excess thrust from the high-lift propellers begin to approach zero. This means that even if the absolute magnitude of the drag is overpredicted somewhat here, windmilling of the wingtip propellers would only be required at speeds near stall.

Ultimately, the Linear $C_{L_{\mathrm{AOA}}}$ approach is preferred over the Minimum Blowing approach because the changes in propeller operating conditions and excess thrust with velocity are less drastic than those in the minimum blowing profile. These more gradual changes can aid the pilot in adjusting the cruise propeller throttle settings as speed is varied so that the aircraft can be flown in a manner that is very similar to how typical aircraft are operated today.

Fig. 8 shows the aircraft performance assuming a maximum blowing approach profile where the motor has a maximum torque of $21 \mathrm{~N}-\mathrm{m}$ (or approximately $15.5 \mathrm{ft}-\mathrm{lb}$ ). For this profile, the maximum torque is maintained as constant throughout the entire approach, which causes the power required to decrease slightly as the flight speed is decreased as shown in Fig. 8(e). ${ }^{\mathrm{m}}$

For the X-57 to maintain $C_{L}$ margins on par with existing GA aircraft, approach speeds of approximately 66 to 73 knots could be flown. These speeds are lower than both the 70-75 knot or 73-82 knot ranges mentioned above for the linear $C_{L_{\mathrm{AOA}}}$ or minimum blowing profiles, respectively. Although this appears to be desirable, approaches flown at speeds less than the unblown stall speed - approximately 73 knots - could result in a potentially unsafe situation. Specifically, consider, for example, what would occur if there were to be a total power failure when flying a stabilized approach at 68 knots. To re-enter a stabilized approach in this situation, the pilot would have to push the nose down, accelerate to a speed above 73 knots, and then re-stabilize the aircraft. During this process, the aircraft would lose altitude and be susceptible to enter a stall/spin - both of which are very dangerous when flying approaches at low altitudes. Consequently, an effective minimum approach speed is 73 knots, which makes the airspeed at which this approach can be flown effectively equivalent to the linear $C_{L_{\mathrm{AOA}}}$ and minimum blowing profiles.

Fig. 8(b) indicates that there is a good $C_{L}$ margin throughout the entire profile, and all of the margin comes from angle of attack (since by definition there is no additional blowing that can be utilized). Although this appears to indicate that the maximum blowing approach is a desirable option, Fig. 8(c) indicates that the maximum blowing approach may be impossible to fly since the excess thrust is noticeably above zero. In this case, windmilling from the cruise propellers is required to decrease the total excess thrust to zero (or below). Additionally, the total power required (even while accounting for the negative power from the wingtip propellers) is higher in this approach than in the linear $C_{L_{\mathrm{AOA}}}$ profile, which makes this less desirable from an energy required/total aircraft range perspective. Finally, because windmilling is required to even reach a $3^{\circ}$ glideslope, there is relatively little flexibility to fly steeper approaches (i.e., glideslopes greater

\footnotetext{
m The "stair-step" nature of the power curves in Fig. 8(e) result from rounding in the outputs of XROTOR. In reality, a smooth profile is to be expected from the maximum to minimum power required.
} 


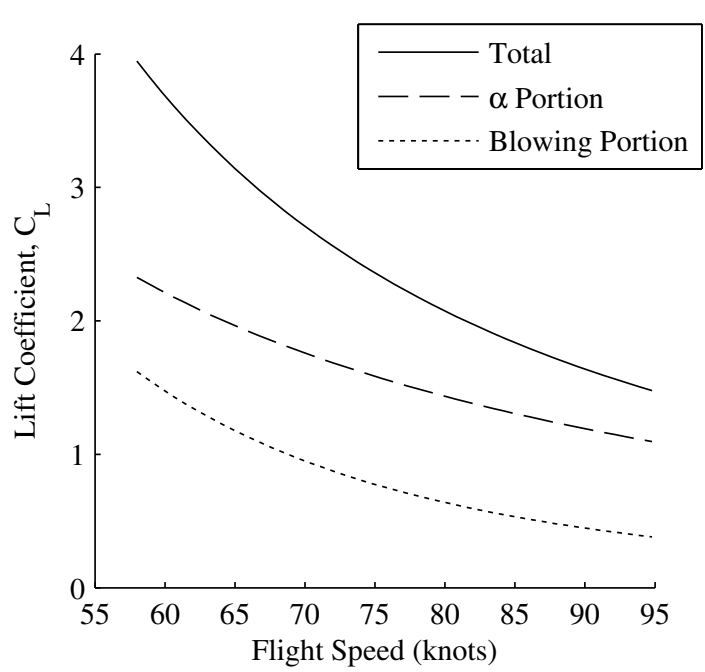

(a) Approach profile

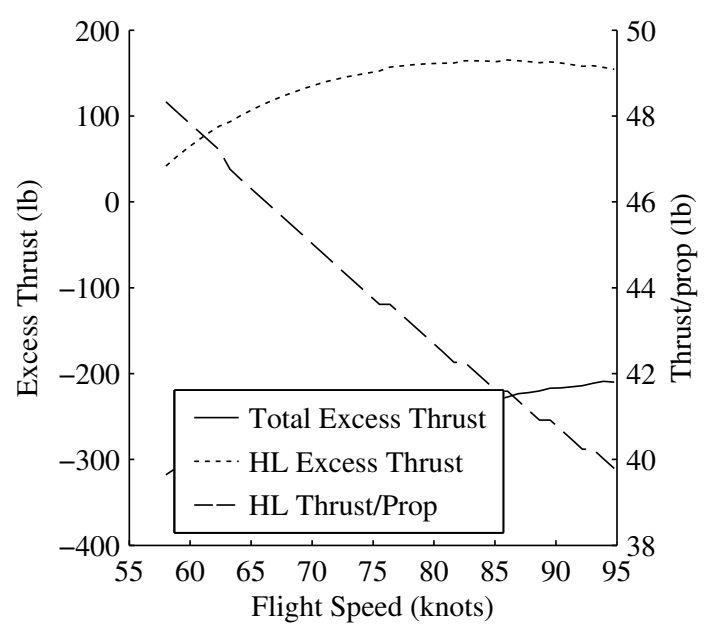

(c) Total excess thrust and high-lift propeller thrust

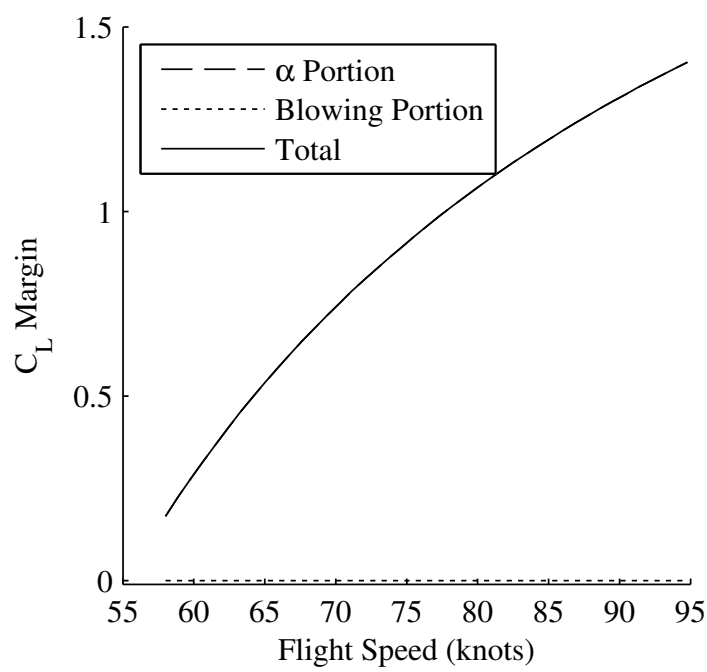

(b) Lift coefficient margin profile

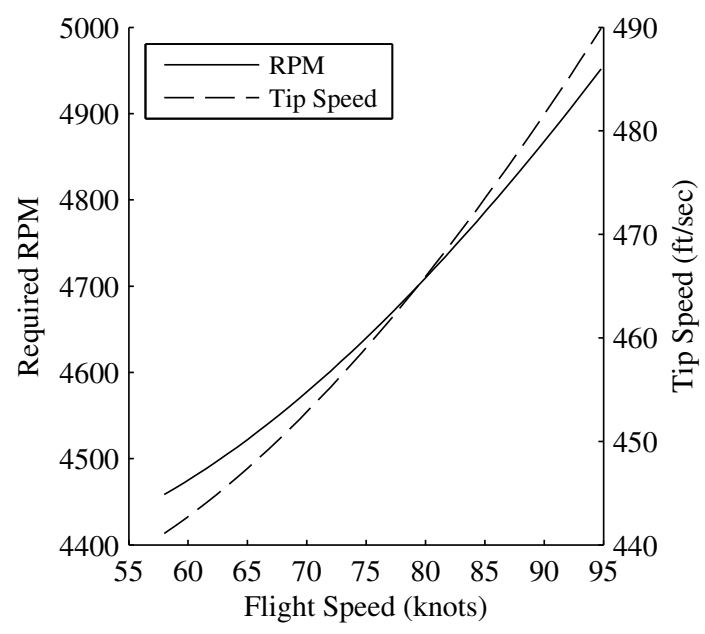

(d) High-lift propeller RPM and tip speed

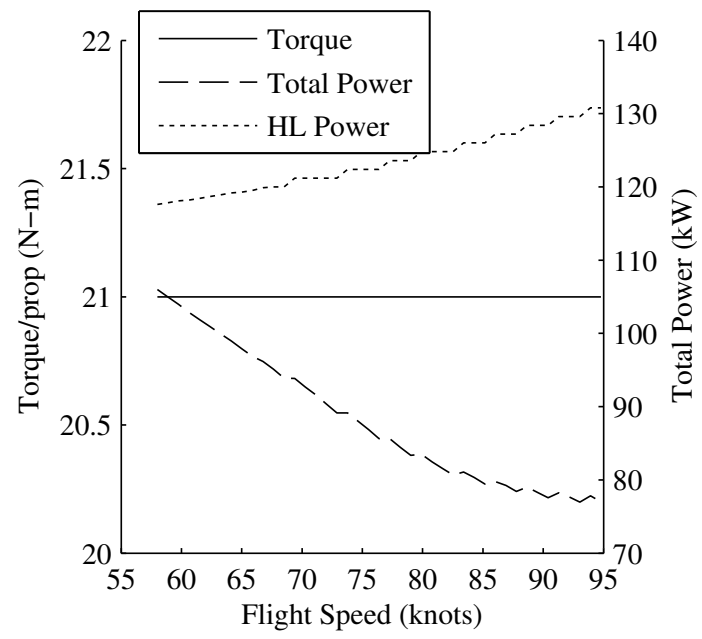

(e) High-lift propeller torque and total power

Figure 8. Maximum blowing (i.e., constant $21 \mathrm{~N}-\mathrm{m}$ of torque) approach profile simulation results

\section{4 of 18}


than $\left.3^{\circ}\right)$.

\section{Altitude Considerations}

The discussion thus far has effectively ignored the variation of performance with altitude - i.e., the results presented above were performed assuming sea level standard conditions. However, aircraft performance in general varies with altitude. In this section we consider the impacts of altitude on the control of the high-lift propellers and the resulting aircraft performance.

Before altitude variations can be considered, one must specify the performance variation that is desired as altitude changes. Specifically, if we desire that the aircraft stall at the same true airspeed as altitude increases, the requirements on the high-lift system will vary from the requirements if we desire that the aircraft stall at the same calibrated airspeed. Because the former Part 23 regulations defined the stall speeds as calibrated airspeeds ${ }^{20}$ and the current ASTM standards maintain this same definition, ${ }^{21 \mathrm{n}}$ we will assume that the same stall speed in calibrated airspeed with altitude is to be maintained. This implies that as the altitude increases, the true airspeed at which the aircraft stalls will increase.

To study the impacts of varying altitude on the high-lift propellers, simulations with XROTOR were performed varying the altitude from sea level to 10,000 ft for the X-57's geometry. We determined the required propeller operating conditions to maintain the desired 3,000 lb of lift at a 58 knot calibrated airspeed for each altitude. The resulting high-lift propeller and aircraft performance are shown in Fig. 9.

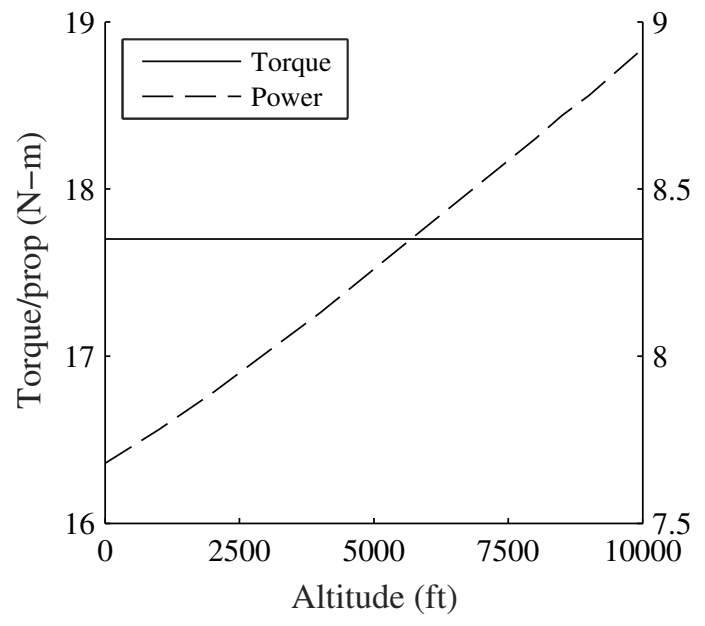

(a) High-lift propeller torque and power

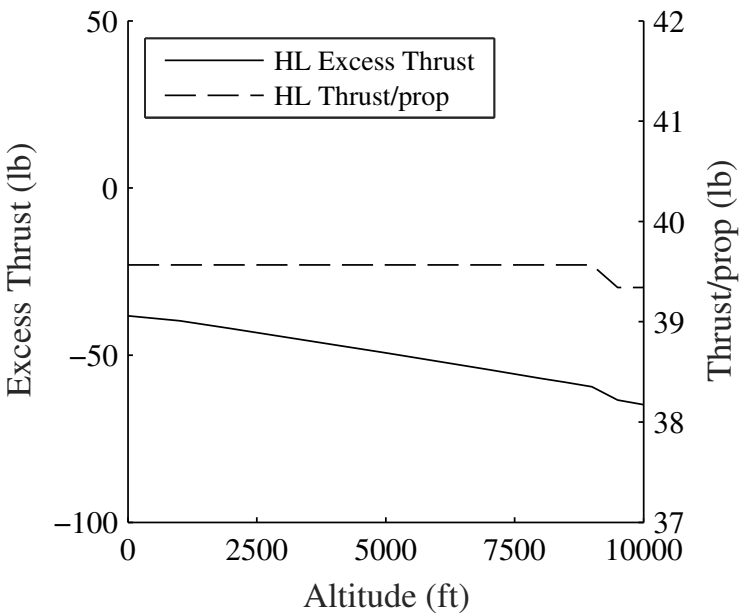

(b) Excess thrust and high-lift propeller thrust

Figure 9. Variation of propeller and aircraft performance with altitude to maintain a 58 knot calibrated airspeed stall

Fig. 9(a) plots the required torque and power of each high-lift propeller over the range of altitudes. Interestingly, the torque required is constant with altitude while the power required increases with altitude. This implies that the propeller speed (RPM) must also increase with altitude. If the "throttle" control for the high-lift propellers controls torque, then the same throttle setting can be maintained over all altitudes to fly the desired approach profile. However, if the throttle instead controls power, the throttle setting must be increased as altitude increases. Additionally, the increase of power with altitude indicates that the total energy required to fly at low speeds with high-lift propellers operating will increase as altitude increases. This implies that when mission planning, the (density) altitude in the location where this low-speed operation is to be performed must be considered.

The thrust of each high-lift propeller and an estimate of the excess thrust of the aircraft over the range of altitudes analyzed is plotted in Fig. 9(b). Interestingly, the thrust from each propeller is effectively constant with altitude while the excess thrust shows a slight decrease with altitude. The decrease in excess thrust with altitude implies that the pilot will need differing values of thrust from the cruise propellers as approaches

\footnotetext{
${ }^{\mathrm{n}}$ See $\S 4.2$ of this standard
} 
are flown at varying altitudes. This change in drag results from a change in the induced velocity from the propellers, which will impact the induced drag as described in Eq. 5. Further study is required to determine if this drag variation is realistic or simply a shortcoming of the current induced drag model.

\section{Recommendations}

Based on the three approach profiles presented in this paper and exploratory work of other approach profiles presented in Ref. 9, we recommend that the X-57 be flown on a profile similar to the Linear $C_{L_{\mathrm{AOA}}}$ approach profile. This profile provides a gradual increase in propeller blowing with decreased flight speed, a balanced $C_{L}$ margin between angle of attack and blowing, a low likelihood of requiring additional drag to maintain a steady approach at any speed, and a relatively simple and intuitive manner of controlling the angle of attack and blowing throughout an approach. Additionally, because there is no excess thrust from the highlift propellers, the option exists to fly a steeper approach more easily than if windmilling from the cruise propellers were required to maintain a $3^{\circ}$ glideslope. This provides the operator a degree of flexibility that would not be present with approach profiles such as the maximum blowing approach where large amounts of windmilling are likely required to fly the relatively shallow $3^{\circ}$ glideslope.

Additionally, we recommended that the high-lift propellers be controlled automatically via a control system that modifies the propeller torque as a function of calibrated airspeed. This torque schedule with calibrated airspeed should provide virtually identical low-speed performance at the same calibrated airspeed across all altitudes, which would make the stall characteristics of aircraft with high-lift propellers similar to those of conventional aircraft. There are several reasons for employing an automatic control system. First, it may be impractical to expect the pilot to control 14 "throttle levers" for each of the X-57's electric motors. Additionally, even if an experienced pilot could manage each of these levers and/or each high-lift prop could be controlled with a single lever, it would be incredibly difficult for a pilot to match the torque dictated by the desired approach profile when manually flying the aircraft. An automatic high-lift propeller controller would allow the pilot to fly an approach in virtually the same manner as is currently done. Furthermore, an automated high-lift propeller torque control would automatically adjust the high-lift propellers' settings to account for wind gusts or other disturbances. This automated system is likely to respond more quickly than the pilot, which should increase the safety of the aircraft.

Finally, recall that the new Part 23 regulations require there to be a "stall speed safety margin" during approach. Although it may be possible for the total $C_{L}$ margin, which is roughly equivalent to a speed margin, to be approximately the same as existing aircraft at relatively low speeds (e.g., as low as approximately 66 knots in the maximum blowing profile for the X-57 described above), it is theoretically possible for there to be a complete loss of power to the high-lift system, which makes approaching at speeds below the unblown stall speed dangerous. A full power loss could be caused by the aircraft exhausting its usable supply of energy or experiencing a malfunction in the electrical system. Although such events should be incredibly rare with a well-designed power system ${ }^{\circ}$ and reasonable pilot situational awareness, we recommend that the reference approach speed and the majority of an approach be flown at speeds equivalent to or greater than the unblown stall speed of the aircraft so that the pilot could adjust the angle of attack at the same airspeed (or even lose some airspeed) and generate sufficient lift with no blowing. Such an approach should satisfy the regulatory language for stall speed safety margin even in very rare scenarios. In the case of X-57, this implies that the approach should be flown at a speed greater than 73 knots.

\section{Summary and Conclusions}

Aircraft such as the X-57 with high-lift propellers have unique lift-producing capabilities that require aircraft designers and operators to re-think the performance and operation of these aircraft. The ability of these aircraft to produce lift in a particular configuration and at a certain airspeed by modifying the blowing from the high-lift propellers adds an additional degree of freedom in lift generation compared to conventional aircraft that rely strictly on modifying the angle of attack. This additional degree of freedom provides both opportunities and challenges. For example, there is the opportunity of creating the required lift in many different manners, but there is the challenge of ensuring that the manner in which that lift is generated is

\footnotetext{
o A total power failure should be incredibly rare in the X-57 due to redundancy in the power system design. Specifically, there are two independent battery packs and two separate buses, each of which powers half of the high-lift motors making a sudden, total loss of power a very unlikely scenario. See Ref. 11 for more information.
} 
safe.

The safety of any aircraft is of paramount importance, and one manner of helping ensure safety is through compliance with Federal Aviation Regulations. The specific regulations regarding the certification of small aircraft-i.e., 14 CFR $\S 23$ - have recently undergone changes that may now enable an aircraft like the X57 with high-lift propellers to be certified. We discussed the new regulations pertinent to the low-speed performance of aircraft when flying an approach prior to landing, and compared these new regulations to the previous regulations. We argued that the "stall speed safety margin" required in the regulations is nearly equivalent to a lift coefficient margin, which is a useful parameter for comparing the safety of high-lift propeller aircraft with conventional aircraft.

We presented three examples of how the total lift for an aircraft with high-lift propellers can be generated from angle of attack and blowing across a range of speeds. By studying the estimated performance of the X-57 over these "approach profiles" and considering the benefits and drawbacks of each, we recommended flying an approach similar to the Linear $C_{L_{\mathrm{AOA}}}$, which provides a balanced amount of lift from both blowing and angle of attack. Such an approach provides safety margins in both angle of attack as well as blowing and should be relatively intuitive for a pilot to fly. Furthermore, we recommended that high-lift propellers be controlled by an automated control system that varies the torque to the high-lift propellers as a function of the calibrated airspeed. We also recommended that a stabilized approach be flown at a speed above the unblown stall speed of the aircraft.

Finally, it is important to remember that the performance estimates shown in this paper for the X-57 were generated with conceptual design level methods. These methods likely provide correct trends, but are certainly not precisely accurate. Additional higher-fidelity modeling and, potentially, wind tunnel testing of the X-57 during approach-like conditions will be performed prior to the actual operation of the aircraft, and ultimately flight testing will be required to determine the precise aircraft performance.

\section{Acknowledgments}

This work was funded under the Flight Demonstration Capabilities project of the Integrated Aviation Systems Program as well as the Convergent Aeronautics Solutions and Transformational Tools and Technologies Projects of the Transformative Aeronautics Concepts Program.

\section{References}

${ }^{1}$ Moore, M. D., Goodrich, K., Viken, J., Smith, J., Fredericks, B., Trani, T., Barraclough, J., German, B., and Patterson, M., "High Speed Mobility through On-Demand Aviation," 2013 Aviation Technology, Integration, and Operations Conference, Los Angeles, CA, August 12-14 2013, AIAA 2013-4373.

${ }^{2}$ Moore, M. D. and Fredericks, B., "Misconceptions of Electric Aircraft and their Emerging Aviation Markets," 52nd Aerospace Sciences Meeting, 2014, AIAA 2014-0535.

${ }^{3}$ Miranda, L. R. and Brennan, J. E., "Aerodynamic Effects of Wingtip-Mounted Propellers and Turbines," 4th Applied Aerodynamics Conference, San Diego, CA, June 9-11 1986, pp. 221-228, AIAA-86-1802.

${ }^{4}$ Smith, Leroy H., J., "Wake Ingestion Propulsion Benefit," Journal of Propulsion and Power, Vol. 9, No. 1, Jan - Feb 1993, pp. 74-82.

${ }^{5}$ Patterson, Jr., J. C. and Bartlett, G., "Effect of a Wing-Tip Mounted Pusher Turboprop on the Aerodynamic Characteristics of a Semi-Span Wing," 21st AIAA, SAE, ASME, and ASEE Joint Propulsion Conference, Monterey, CA, 8-10 July 1985, AIAA 85-1286.

${ }^{6}$ Patterson, Jr., J. C. and Bartlett, G. R., "Evaluation of Installed Performance of a Wing-tip-Mounted Pusher Turboprop on a Semispan Wing," Nasa-tp-2739, National Aeronautics and Space Administration, 1987.

${ }^{7}$ Moore, M. D., Clarke, S., Stoll, A., Clark, A., MacAfee, S., and Foster, T., "Affordable Flight Testing of LEAPTech Distributed Electric Propulsion," http://nari.arc.nasa.gov/sites/default/files/MooreSeedling.pdf, January 13-15 2015, NASA Aeronautics Research Mission Directorate 2015 LEARN/Seedling Technical Seminar.

${ }^{8}$ Borer, N. K., Patterson, M. D., Viken, J. K., Moore, M. D., Clarke, S., Redifer, M. E., Christie, R. J., Stoll, A. M., Dubois, A., Bevirt, J., Gibson, A. R., Foster, T. J., and Osterkamp, P. G., "Design and Performance of the NASA SCEPTOR Distributed Electric Propulsion Flight Demonstrator," 16th AIAA Aviation Technology, Integration, and Operations Conference, AIAA Aviation, Washington, D.C., June 13-17 2016, AIAA 2016-3920.

${ }^{9}$ Patterson, M. D., Conceptual Design of High-Lift Propeller Systems for Small Electric Aircraft, Ph.D. thesis, Georgia Institute of Technology, August 2016, [upcoming publication].

${ }^{10}$ Patterson, M. D., Derlaga, J. M., and Borer, N. K., "High-Lift Propeller System Configuration Selection for NASA's SCEPTOR Distributed Electric Propulsion Flight Demonstrator," 16th AIAA Aviation Technology, Integration, and Operations Conference, AIAA Aviation, Washington, DC, 13-17 June 2016, AIAA 2016-3922.

${ }^{11}$ Clarke, S., Redifer, M., Papathakis, K., Samuel, A., and Foster, T., "X-57 Power and Command System Design," engrXiv, 2017. 
${ }^{12}$ Raymer, D. P., Aircraft Design: A Conceptual Approach, American Institute of Aeronautics and Astronautics, 4th ed., 2006.

${ }^{13}$ Stoll, A. M., "Comparison of CFD and Experimental Results of the LEAPTech Distributed Electric Propulsion Blown Wing," 15th AIAA Aviation Technology, Integration, and Operations Conference, Dallas, TX, 22-26 June 2015, AIAA 20153188.

${ }^{14}$ Kinney, D. and McDonald, R., "VSPAero / OpenVSP Integration," http://www.openvsp.org/wiki/lib/exe/ fetch.php?media=workshop15:vspaero_2015.pdf, August 2015, accessed 18 April 2016.

${ }^{15}$ Conway, J., "Analytical Solutions for the Actuator Disk with Variable Radial Distribution of Load," Journal of Fluid Mechanics, Vol. 297, August 1995, pp. 327-355.

${ }^{16}$ Johnson, W., Helicopter Theory, Dover Publications, Inc, New York, 1980.

${ }^{17}$ Drela, M. and Youngren, H., "XROTOR Download Page," http://web.mit.edu/drela/Public/web/xrotor/, accessed 26 May 2014.

${ }^{18}$ Litherland, B. L., Patterson, M. D., Derlaga, J. M., and Borer, N. K., "A Method for Designing Conforming Folding Propellers," 17th AIAA Aviation Technology, Integration, and Operations Conference, AIAA Aviation, 2017.

${ }^{19}$ Joby Motors, "Products," http://www.jobymotors.com/public/views/ pages/products.php, 2011, accessed 16 Oct., 2015.

20 "Stalling speed," Title 14 Code of Federal Regulations Part 23 Section 49, 2011.

${ }^{21}$ ASTM Standard F3179/F3179M - 16, Standard Specification for Performance of Aeroplanes, 2016. 